saline medicines, the inhalation of iodine rapour, and, pre-eminently iron. Having mentioned the latter medicine, we are induced to remark how frequently authors in one portion of a work contradict something that has been said in another portion of it. Dr. Cook says, at page 98," It appears highly probable, from some experiments made by Coster on the lower animals, that, in addition to its anti-hectic properties in consumption, iron posseses a specific or peculiar power of counteracting the tuberculous diathesis." At page $63 \mathrm{he}$, as may be judged from the tenor of his remarks, has denied the spccific properties of all medicinal agents. At page 81 he unconditionally praises Madeira as a place of residence for consumptive invalids, although no farther back than page 77 he had said, "It is now generally acknowledged that a residence on the coast is rather prejudicial than productive of benefit in consumption." Fault is not to be found with Dr. Cook for recom. mending an insular residence, such as $\mathrm{Ma}$ deira, for consumptive invalids; for experience tends to show that a maritime situation has proved highly beneficial to phthisical patients who have been induced to walk daily on a beach, close to the sea, inhaling the air as it comes from off the waves. On a prima facie view, indeed, such a course ought to be attended with the best results, if iodine (as such air must be charged with) exert a salutary effect in promoting the absorption of tuberculous matter. Neither do we quarrel $w$ ith Dr. Cook for his advocacy of iron; for probably great benefit may accrue from the union of the two remedies, in the proto-iodide of iron which has lately been used on the continent, with decisive success, against phthisis. For a peculiar method of employing iodine in consumption we may refer the reader to Mr. Flood's "Exposition of the Fathology and Treatment of Tubercular Phthisis," reviewed in the last rolume of this Journal, page 688; meanwhile to those persons who are fond of examining the last works on particular subjects in preference to any other's, the work of Dr. Cook may be presented as a correct synopsis of modern information in relation to the disease to which it is devoted.

M. Ricord supposes that the exudation of blood occurring after cauterisation of the os tincre has deceived individuals jnto the belief that applications of nitrate of silver promote or restore menstruation.

\section{TREATMENT BY COLD WATER.}

\section{To the Editor of The LANCET.}

Srr,-You have published from time to time various severe strictures upon the method of treating disease by the combined operation of sweating and the several applications of cold water; and you have given insertion to absurd letters, many of them mere quack advertisements of their own cures, from correspondents respecting this system. Dr. Dick, and other chirping critics, have been permitted, through your columns, to obtrude their ignorant impertinence upon the public; and sundry anony. mous scribblers have been favoured with a similar opportunity of appearing in print through the same gratuitous channel.

The effect of this has been that the public has become more and more prejudiced in favour of the vely system which has been opposed in so injudicious a manner. We see hydropathic institutions springing up in all directions, and publications on the sub. ject bidding fair to rival those on quick. silver, saltpetre, or any other esteemed drug.

Now, if you wish the merits of hydropa. thy really to be canvassed, and its medicinal effects to be accurately ascertained, the course which $I$ would suggest as the best is that you should, on your own authority, and with proper brevity and clearness, state what you consider to be the objections to which it is liable, whether practical or theoretical. Water practitioners will then see what is actually advanced against their doctrine, and no doubt they will readily furnish a reply to your remarks. I, for one of the humblest and most sincere among them, hereby offer, and pledge myself, to refute, with all possible conclusiveness, whatever you can produce to this effect, whe. thel it regards the principles on which hydropathy is grounded, or the practical effects it has produced. I $\mathbf{2 m}$, Sir, your obedient servant,

Sherborne-House, Cheltenham,

JAS. FREEMAN, M.D. July $4,1843$.

* Of Dr. Freenan we know nothing but that his name closes the above letter. Whatever we may say, therefore, on this occasion can have no personal application to that gentleman, although we must confess that if our judgment were called for upon him, individually, we could find some evi. dence of his fitness to speak to facts, in his declaration that "hydropathy" has thriven in proportion as it has been condemned. Or else we might regard him as a sorry blunderer for supposing the necessary consequence of notoriety and curiosity to be the result of well-tempered feeling and wisdom. 
England is the paradise of quacks, where whoever cries very loudly will have plenty of followers-for a time. Priessnitz at one period had more than a thousand patients in bis hotel; now the number is three-quarters less. But what we have to say respecting the cold-water scheme must be said at once. HYDROPATHY, then, seems to be THE FORLORN BOPE OF DOCTORS OUT AT ELBOWS.

As for accepting challenges to fight the question, we should as soon think of fencing Barón Duporet, or Mr. MoRison, or Mr. Holloway, or Old Parr, with his life pills. We are not at war with water,-for that healthful beverage and bathing are as old as the hills and the rivers, - but with the quacks who gull the public, and them we destroy without fighting.

\section{TREATMENT OF GONORRHCA.}

\section{To the Editor of THE LANCET.}

Sir, - I am well aware that almost every medical gentleman has some mode of treat. ing gonorthoea which he naturally supposes is a more sure remedy than any other; yet I dare say he often fonds his medicines fail; but when this is the case I doubt not he attributes the failure to anything but the just one-the insufficiency of his treatment. Under these circumstances I do not feel re. luctant to present to you a mode of treatment that I can fully rely upon as generally successful as regards a simple gonorrhcea.

Advise the patient to abstain from all fermented and spirituous liquors; yet this is rarely urged on the patient, as it may lead to suspicion, but it is the duty of a surgeon. nevertheless, to insist upon a "teetotal" diet for at least three or four weeks.

Keep the bowels regular once or twice a day with some saline aperient, and apply round the glans, continually, by means of a slip of lint, a lotion as follows :-

R Solution of acetate of lead, forty minims to one drachm;

Tincture of opium, two drachms;

Rosewnater, three ounces. Mix.

And inject once every four or six hours some of the following:-

R. Solution of acetate of lead, half a drachm;

Wine of opium, two drachms;

Orange flower.water, two ounces and a half. Mix.

I have followed this mode of treatment in fourteen successive cases with the best results. That injections of a proper strength produce hernia humoralis, or stricture, is too absurd for further notice.

But I may add, that the violent scalding during making water arises much from the great acidity of the urine. Sesquicarbonate of soda and liquor potassæ, given every four hours, will remove this. The most horrid torture in making uater has disappeared with this treatment. I am, Sir, your obedient servant,

July 3, 1843 .

J.R.C.

\section{SEA-SICKNESS.}

To the Editor.-Sir: : On a recent aquatic excursion I was, as usual, very sick. I tried brandy, soda-water, coffee, \&c., without the slightest benefit. A lady on board was using brandy and salt for some purpose which I did not inquire about, but by mistake she put the salt (a teaspoonful) into a wineglass about half full of vinegar. This I mistook for my brandy, which was by its side, and swallowed. In a few minutes $I$ was delighted to find the sickness much abated, and on taking a second dose was perfectly relieved, having soon afterwards a good appetite, and feeling not the slightest nausea after eating a hearty dinner and drinking two glasses of sherry. I recommended the same remedy to a gentleman who was also very sick. It did not so completely restore him as it had done me, but he told me that althorgh be lad made many voyages, was always sick, and had tried everything that is usually recommended, he had never experienced so much benefit as from the vinegar and salt. I have no opportunity of giving it a more extensive trial, but hope that some of the readers of THE LANCET will gire us the result of further ex. perience, with information as to whether either the salt or the vinegar, taken singly, will have the same effect. Yours,

July $6,1843$.

\section{A Freshwater SaIlor。}

OPFTHALMIA AND SUDDEN BLINDNESS.

A RIDDLE IN MEDIOINE.

A VINE-DRESSER of Sauterne, aged $\mathbf{3} 3$, had, for three days, felt a slight inflammation in the conjunctiva of the left eye, but of scarcely enough annoyance to require him to seek medical advice. On the evening of the third day he went to bed as usual and slept soundly until five o'clock the next morning, when, on awaking, he found himself quite blind on that side! On being examined, three days afterwards, the eyelids were found inuch swollen and the conjunc. tiva greatly injected; there was chemosis; the cornea had lost its transparency, and pus existed between its layers, as well as in the anterior chamber, mixed with the aqueous humour. The iris looked "like a dead leaf," and, in fact, all the membranes and humours of the eye, totius substantia, were in the most inexplicable condition. The patient suffered little or no pain. He is stated to have never been the subject of 